\title{
Metabolic Alkalosis Associated Fluid and Electrolyte Disorders Revealing an Upper Digestive Tract Condition
}

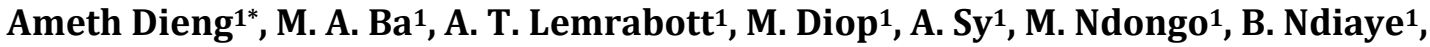 \\ M. S. Diawara², M. Faye', Mo Faye ${ }^{1}$, B. Ba ${ }^{1}$, N. Keita1 ${ }^{1}$, S. Diagne1, M. M. Cissé2 \\ ${ }^{1}$ Department of Nephrology, Dialysis and Kidney Transplant in Hospital Aristide Le Dantec, Dakar, Senegal \\ ${ }^{2}$ Department of Nephrology and Dialysis in Regional Hospital, Thies, Senegal \\ Email: *methjeng@gmail.com
}

How to cite this paper: Dieng, A., Ba, M.A., Lemrabott, A.T., Diop, M., Sy, A., Ndongo, M., Ndiaye, B., Diawara, M.S., Faye, M., Faye, M., Ba, B., Keita, N., Diagne, S. and Cissé, M.M. (2020) Metabolic Alkalosis Associated Fluid and Electrolyte Disorders Revealing an Upper Digestive Tract Condition. Open Access Library Journal, 7: e6338.

https://doi.org/10.4236/oalib.1106338

Received: April 20, 2020

Accepted: August 15, 2020

Published: August 18, 2020

Copyright $\odot 2020$ by author(s) and Open Access Library Inc.

This work is licensed under the Creative Commons Attribution International License (CC BY 4.0).

http://creativecommons.org/licenses/by/4.0/

\begin{abstract}
We report a case of a 66-year-old female patient with ischemic cardiomyopathy, who was referred in Nephrology Department for the management of a renal impairment associated-severe hyponatremia, hypokalemia and hypochloremia that occurred after vomiting episodes evolving since 1 month. On admission, the patient was calm with a psychomotor retardation occurring in a context of moderate dehydration. Arterial blood gas analysis outlined a severe metabolic alkalosis. An extra-renal cause of these metabolic disorders was retained on the basis of a metabolic alkalosis not featuring an HBP and the urinary ionogram revealing low urine sodium, potassium and chlorine. The seriousness of the clinical course was made by the underlying cardiomyopathy condition, hypocalcemia, severe consistent hypokaliemia and compensatory hypoventilation. The evolution was unremarkable after 4 days of hydro-sodium deficit correction with potassium chloride adjunction. It featured a drowsiness disappearance and a good temporal-spatial orientation. The clinical examination revealed a good general condition associating a good hydration and hemodynamic state. The lab findings showed a normal plasma sodium levels and increased kalemia and chloremia. Upper digestive endoscopy outlined a hiatal hernia associated-erosive bulbitis indicating an eradicator treatment of Helicobater pylori based on a double dose of PPI (Omeprazole $20 \mathrm{mg}$ ) and dual antibiotic therapy (Amoxicillin and Clarithromycin) combined with domperidone.
\end{abstract}

\section{Subject Areas}

Anaesthesiology \& Pain Management, Cardiology, Diabetes \& Endocrinology, Gastroenterology \& Hepatology, Internal Medicine, Metabolic Sciences, 
Nephrology, Neurology, Pathology

\section{Keywords}

Metabolic Alkalosis, Hypokalemia, Hyponatremia, Chloruria, Vomiting, Bulbitis, Hatial Hernia

\section{Introduction}

Chronic vomiting is often responsible for fluid and electrolytes disorders including metabolic alkalosis. The pathogenesis features two mechanisms: the generation and alkalosis maintenance. The increase of plasmatic bicarbonate concentration originated from the digestive tract is due to an excessive $\mathrm{H}^{+}$proton secretion through the distal nephron. Fluid and electrolytes disorders resulting from it; including hypokalemia, chlorine deficit, hypovolemia and secondary aldosteronism, are involved in the increase of proximal tubular reabsorption of bicarbonate and/or the increase of distal tubular acid secretion [1]. It is not often symptomatic to be the frontline of the clinical course.

\section{Observation}

We report the case of a female patient of 66 years of age, follow in Cardiology for an ischemic cardiomyopathy under Carvedilol, Molsidomin and Aspirin, who were referred to the Nephrology Department for the management of electrolyte disorders.

Laboratory investigations performed before her admission outlined a mild renal function impairment with a plasma creatinin levels at $13.3 \mathrm{mg} / \mathrm{l}$ corresponding to a GFR of $51.5 \mathrm{ml} / \mathrm{min}$ according to the MDRD, low plasma sodium levels at $119 \mathrm{mmol} / \mathrm{l}$, hypokalemia at $2.5 \mathrm{mmol} / \mathrm{l}$, hypochloremia $<50 \mathrm{mmol} / \mathrm{l}$, normal plasma calcium levels at $89.8 \mathrm{mg} / \mathrm{l}$ and hypophosphatemia at $22.8 \mathrm{mmol} / \mathrm{l}$ (Table 1). We performed a TSHus dosage, on the basis of neuro-psychiatric symptoms on an underlying cardiomyopathy condition, that was normal at 1.49 $\mu \mathrm{UI} / \mathrm{ml}$ allowing to not consider a hypothyroidism. The ECG revealed an ancient left bundle branch block, left ventricular hypertrophy and ancient necrosis on antero-septal area.

The anamnesis found early post-prandial vomitings evolving for 1 month associating obstipation without abdominal pain in a context of intense physical asthenia and anorexia. This is followed by a diurnal drowsiness with short awareness loss for less than 5 minutes, spontaneously reversible.

On admission, the clinical examination revealed a calm patient with psychomotor retardation and moderate dehydration. The blood pressure (BP) was normal with no featuring fever. Cardiac and pulmonary examination was unremarkable. Neurological examination didn't highlight sensitivo-motor deficit and the reflexes was present and normal. The rectal examination found a fecal impaction. 
Table 1. Biological parameters evolution before and during hospitalisation.

\begin{tabular}{ccccc}
\hline Laboratory investigations & $\begin{array}{c}\text { Before } \\
\text { hospitalisation }\end{array}$ & D2 & D4 & D6 \\
\hline Sodium $(\mathrm{mmol} / \mathrm{l})$ & 119 & 127 & 134 & 135 \\
Potassium $(\mathrm{mmol} / \mathrm{l})$ & 2.5 & 1.7 & 2.34 & 3.77 \\
Chlorine $(\mathrm{mmol} / \mathrm{l})$ & $<50$ & 68 & 86 & 98 \\
$\mathrm{pH}$ & - & 7.58 & - & 7.42 \\
Bicarbonatemia $(\mathrm{mmol} / \mathrm{l})$ & - & 48.5 & - & 29 \\
PaCO $(\mathrm{mmHg})$ & - & 52.1 & - & 46 \\
PaO $2(\mathrm{mmHg})$ & - & 60 & - & - \\
Urea $(\mathrm{g} / \mathrm{l})$ & - & 0.94 & - & 0.37 \\
Creatininemia $(\mathrm{mg} / \mathrm{l})$ & 13.3 & 10.9 & - & 10.4 \\
GFR $(\mathrm{ml} / \mathrm{min})$ & 51.48 & 64.77 & - & 68.38 \\
Calcemia $(\mathrm{mg} / \mathrm{l})$ & 89.9 & 78.7 & - & - \\
Phosphoremia $(\mathrm{mg} / \mathrm{l})$ & 22.8 & 18.1 & - & - \\
\hline
\end{tabular}

The diuresis was normal at $1400 \mathrm{ml} /$ day.

A second dosage of plasma eloctrolytes revealed similar disorders with a hyponatremia at $127 \mathrm{mmol} / \mathrm{l}$, hypokalemia at $1.7 \mathrm{mmol} / \mathrm{l}$, hypochloremia at 68 $\mathrm{mmol} / \mathrm{l}$. On the basis of the consistency of these abnormalities, we performed arterial blood gas measurement that helped to note a $\mathrm{pH}$ at 7.58 with elevated plasma bicarbonate levels at $48.5 \mathrm{mmol} / \mathrm{l}$ corresponding to a hypochloremic metabolic alkalosis. We noted a compensatory hypercapnia with a $\mathrm{PaCO}_{2}$ levels at $52.1 \mathrm{mmHg}$ and a hypoxemia with a $\mathrm{PaO}_{2}$ at $60 \mathrm{mmHg}$ related to a hypoventilation. The plasma anion gap was at $12 \mathrm{mmol} / \mathrm{l}$ (Table 1 ). Urea and creatininemia were elevated at $0.94 \mathrm{~g} / \mathrm{L}$ and $10.2 \mathrm{mg} / \mathrm{L}$, respectively. A hypocalcemia at $78.7 \mathrm{mg} / \mathrm{L}$ and hypophosphatemia at $18.1 \mathrm{mg} / \mathrm{L}$ were also observed in our patient.

On our patient, the seriousness of the clinical course was made of by the underlying cardiomyopathy condition, hypocalcemia, severe consistent hypokaliemia and compensatory hypoventilation.

The urinary ionogram revealed low urine sodium at $38 \mathrm{mmol} / 24 \mathrm{~h}(40-220)$, potassium at $20 \mathrm{mmol} / 24 \mathrm{~h}(25-125)$ and chlorine at $32 \mathrm{mmol} / 24 \mathrm{~h}(110-250)$.

She underwent a 4-day treatment that comprised normal saline (Nacl 0.9\%) and potassium chloride $(\mathrm{KCl})$ by intravenous route after evaluating the deficits, in combination with antiemetic drugs.

The outcome was unremarkable with a drowsiness disappearance, a good temporo-spatial orientation and the clinical examination found a patient in good general condition, a good hydration and hemodynamic state. According to biological findings, there was an improvement in the numbers with a natremia rated at $132 \mathrm{mmol} / \mathrm{l}$, kalemia at $2.34 \mathrm{mmol} / \mathrm{l}$ and chloremia at $86 \mathrm{mmol} / \mathrm{l}$. However, we continued the treatment with oral potassium supplementation (Kaleor$\left.i^{*}\right)$ and oral hydration. 
Upper gastrointestinal endoscopy performed after correction of metabolic disorders revealed a hiatal hernia associated-erosive bulbitis, then we conducted an eradicator treatment of Helicobater pylori based on a double dose of PPI (Omeprazole $20 \mathrm{mg}$ ) and dual antibiotic therapy (Amoxicillin and Clarithromycin) combined with domperidone.

\section{Discussion}

Our patient presented with multiple metabolic disorders: hyponatremia, hypokalemia, low chloremia, and metabolic alkalosis.

Volemic state analysis as a first step is important in the diagnostic process to distinguish metabolic alkalosis associated with hypovolemia or extracellular volume expansion. Our patient showed signs of dehydration with normal BP; this could be due to hyperactivation of the RAAS.

The etiologic diagnosis is based on the determination of the renal or extra-renal origin of the chlorine and sodium losses, and the urinary ionogram remains essential. During metabolic alkalosis, decreased natriuresis and chloruria suggest extra-renal loss of $\mathrm{NaCl}$ and this can be observed in situations of hypovolemia as in our patient. During vomiting, the loss of chlorine is digestive and is accompanied by equimolar generation of bicarbonate. The induced bicarbonaturia leads to sodium and potassium loss of renal origin, with hypokalemia being secondarily promoted by hyperaldosteronism secondary to hypovolemia.

In view of the contrast between the low urinary excretion of chlorine associated with a decrease in natriuresis initiated by a digestive loss of $\mathrm{H}^{+}$in related to the vomiting, we set the diagnosis of a metabolic contraction alkalosis.

The hypercapnia observed in our patient bears witness to a predictable compensation of the alkalosis tending to bring the $\mathrm{pH}$ back to physiological values; nevertheless this ventilatory response is limited by the hypoxemia it induces.

Maintenance factors found in our patient included hypovolemia with functional renal failure, hypokalemia, and sodium depletion. Normal blood pressure suggests that there was hyperaldosteronism secondary to hypovolemia.

The underlying ischemic heart condition associated-hypokalemia was a threatening situation, especially since hypocalcemia was present.

The etiological research of this vomiting led to the oeso-gastroduodenal fibroscopy (EGDF) showing an erosive bulbitis associated with a hiatal hernia that caused the vomiting in our patient.

The correction of metabolic alkalosis consists of simultaneous correction of both generating (the cause) and maintaining factors of the alkalosis. A targeting correction of the cause is insufficient if the maintaining factors are not treated [2]. In metabolic contraction alkalosis, it is necessary first to correct hypovolemia by normal saline administration. At the same time, this treatment decreases proximal tubular reabsorption of bicarbonate, and corrects hyperaldosteronism secondary to hypovolemia, as well as the sodium deficiency which maintains the 
alkalosis. In hypokalemia, potassium chloride should be administered routinely [3] [4]. Our patient received this protocol in addition to the etiological treatment of her digestive pathology.

The evolution of the clinico-biological symptomatology was unremarkable and then she was discharged after one week of hospitalization.

\section{Conclusions}

Metabolic alkalosis is a disorder accompanying a range of clinical situations such as vomiting. It is rarely symptomatic to be in front of the clinical course. The identification of the generating and maintaining factors such as hypovolemia, hypokalemia, chlorine deficit and secondary hyperaldosteronism are essential for better management. A priori, the etiological diagnosis doesn't raise any problem in a context of obvious clinical situations.

The patient's informed consent was obtained.

\section{Conflicts of Interest}

The authors declare no conflicts of interest regarding the publication of this paper.

\section{References}

[1] Stehle, T., Vidal-Petiot, E. and Flamant, M. (2017) Metabolic Alcalosis. Nephrology Treaty.

[2] Peixoto, A.J. and Alpern, R.J. (2013) Treatment of Severe Metabolic Alkalosis in a Patient with Congestive Heart Failure. American Journal of Kidney Diseases, 61, 822-877. https://doi.org/10.1053/j.ajkd.2012.10.028

[3] Weise, W.J., Serrano, F.A., Fought, J. and Gennari, F.J. (2008) Acute Electrolyte and Acid-Base Disorders in Patients with Ileostomies: A Case Series. American Journal of Kidney Diseases, 52, 494-500. https://doi.org/10.1053/j.ajkd.2008.04.015

[4] Pham Hung, G., Nahon, L. and Grimaud, D. (1991) Conduct to Cope with Metabolic Alkalosis in a Surgical Setting. Annales Françaises d'Anesthésie et de Réanimation, 10, 191-199. https://doi.org/10.1016/S0750-7658(05)80466-6 